\title{
The Impact of Live Animals Exports and Its Implication to Leather and Leather Products Export in Ethiopia
}

\author{
Gebergziaher G. Gebremicael Solomon Alemu Afework H. Mesfin \\ Ethiopian Meat and Dairy Institute, P.O. Box, ebrezeit Ethiopia, Ethiopia
}

\begin{abstract}
The livestock sub-sector plays a significant role in the Ethiopian economy to both agricultural value-added and national GDD. In addition Ethiopian livestock and livestock product exports include finished leather, skins and hides, leather products, live animals and meat. But the sector contributes little to exports as compared to the potential and the output from the sector is underutilized. The emphasis of this study is assessing the impact of the live animal export on the leather products export. The data used in this study were secondary and are mainly obtained from secondary sources and analysed using descriptive analysis and it was fit in multiple regression models to assess the impact of live animals export on leather products export. The first thing in time series analysis is get a view of the time series plot of the variables in the analysis. We found that there is high export of live animals compared to the export of skin and hide, leather and its products. The study proved that value addition activities would improve leather products export in terms of value and volume.
\end{abstract}

Keywords: Export, Industries, Leather, livestock Products

DOI: $10.7176 / \mathrm{JMCR} / 58-03$

Publication date:July $31^{\text {st }} 2019$

\section{INTRODUCTION}

\subsection{Background of the study}

Livestock plays an important role in providing export commodities, such as Meat and meat By-products live animals, hides, and skins, finished leather products and leather products to earn foreign exchanges to the country. In 2014/2015 fiscal year, 3.07 billion litters of cow milk, 233.85 million litters of camel milk, and 106.57 million eggs were produced (CSA, 2015). The livestock management system is predominated by extensive production systems, where indigenous breeds are kept under low-input/low-output husbandry practices. Green pasture $(56.23 \%)$ and crop residues $(30.06 \%)$ are the main feed types available in the country.

Livestock products, including live animals, meat, and leather goods, are a major source of foreign exchange. As one of its economic objectives, the government of Ethiopia is pursuing a policy of maximizing revenues through meat and live animal exports. In the past few years, Ethiopia's volume of meat exports has been rising steadily, though its live animal exports have varied due to external factors that include trade bans by importing countries(Fact sheet: livestock Ethiopia, 2010).

Export volume has increased corresponding with the number and total soaking capacity of tanning industries. The marketing process, on the other hand, follows more of the traditional way without showing any significant change towards modern marketing practices. The hide \& skin industry faces numerous intricate challenges in its development. The problems can be classified into organizational, supply side, demand side, promotional and informational.

Hides \& skins from the highland areas of the country are preferred to those of the lowlands in the foreign market, because these are known to have unique characteristics of compactness and utilizability for different end products for sportswear, garments, gloves, shoes and hand bags for ladies. Recent studies showed that the livestock sector contributes 12-16\% of total Gross Domestic Product and 33-35\% of Agricultural Gross Domestic Product (MoA and ILRI, 2013).

For the development of the livestock sector, a due emphasis is given to the development of the livestock sector in the growth and transformation plan (GTP). The livestock sector is expected to be promoted through expansion of processing and value adding activities. Livestock and livestock products are the major foreign exchange earning sources of Ethiopia, with hides and skins contributing the most. However, with its huge livestock resources development potentials, the contribution of value added livestock products towards the economic development of Ethiopia is still at its infancy stage.

One of the frequently mentioned reasons for the low level export of value added livestock products to the international market is the export of live animals both legally and illegally among others. Although exporting value added livestock products is the focus of Ethiopian Government to earn the best possible foreign exchange from our Livestock resources, the export of Live animals make a considerable contribution to Ethiopian economy in terms of export Earnings, a large number of the country's ruminants have been traditionally smuggled to neighbouring countries. Reports from custom and Inland Revenue shows that illegal sale of livestock is practice with the neighbouring countries of Somalia and Kenya, and Sudan and Djibouti.

Given the fore mentioned issues, it is worth to study and quantify the impact of the live animal export on 
livestock products in Ethiopia to consider the lessons on the nature of industries which engaged in the production and export of livestock value added products in Ethiopia during the analysis period. Therefore, given the untapped potential of the livestock resource, it is important to establish relationship between export demand and its determinant factors to reap more benefits from the sector in Ethiopia.

\section{Materials and Methods}

\subsection{Description of the study area}

The study has a national coverage of the Federal Democratic Republic of Ethiopia (FDRE) with total area of is 1.14 million square kilometres (CSA, 2014). Ethiopia is a multi-ethnic state with diverse languages. Ethiopia is Located in the north-eastern part of Africa, commonly known as the Horn of Africa, at the cross-roads between Africa, the Middle East and Asia. The country has a relatively stable political and economic environment.

Ethiopia is endowed with abundant natural resources. Altitude in Ethiopia ranges from 125 meters below sea level in the Danakil depressions of the Afar region to 4,620 meters above sea level in the Amhara region. Thus the country has 18 major and 49 sub agro-ecological zones, each with its own agricultural and biological potential. It possesses one of the largest and most diverse genetic resources in the world. Besides, it has the soils and the climate suitable for the production of a variety of food crops. The Ethiopian economy is based on agriculture and depends on foreign currency earnings.

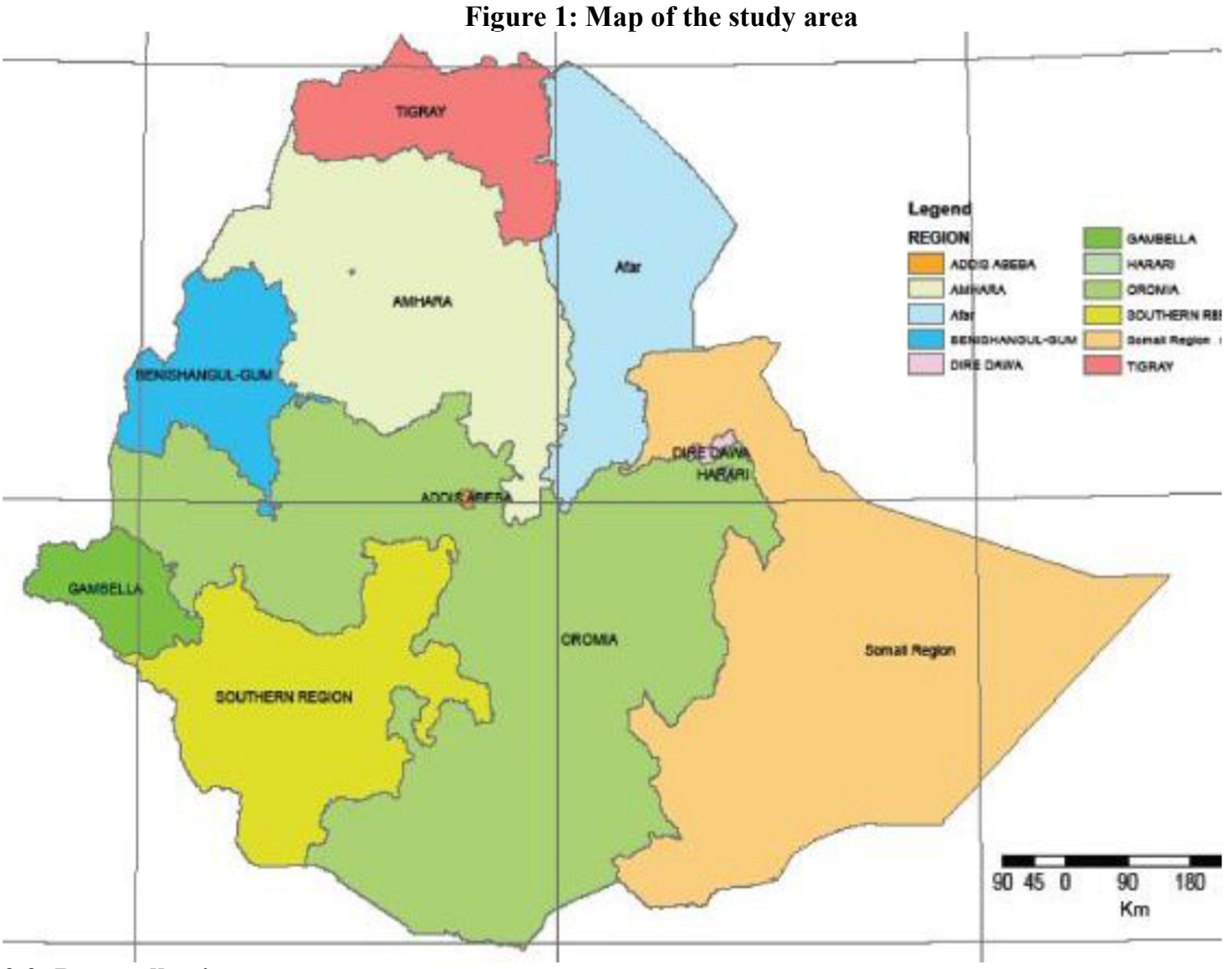

\subsection{Data collection}

Both qualitative and quantitative data were used to capture the advantages and disadvantages of qualitative and quantitative data sets. To analyze the data quantitative research approach and descriptive statistic analysis was used. Key informants interview, time series secondary data sets, secondary data (documentary analysis) like environmental policies and plans, reports, audit reports, rules and regulations related to Meat were collected from National bank of Ethiopia, Ethiopian Customs Authority, Food and Agricultural Organization, World bank and Economy Watch. Hence, data related to the value and volume of Ethiopian meat and live animals export, the export value and volume of meat from each category (sheep, goat and cattle meat), the value and volume of Ethiopian leather products export, and the value and volume of Ethiopian Raw hides and skins and finished leathers export were collected from different sources.

\subsection{Data Analysis}

Descriptive analysis is used to analyze live animal exports. However, processing of livestock in the form of meat 
and other products may generate improved revenue adding to their value whilst helping in overcoming problems like transportation and bans; which is more serious in the case of live animals. Hence, due to the nature of data, for meat exports both descriptive analysis and econometric analyses were employed to estimate the magnitude of the impact assessment factor. Interpretation of the data calls for a variety of analysis techniques. The data for background information and markets is analyzed with descriptive method, and the data for empirical modeling is analyzed systematically using software package (STATA 12) that can handle relatively recent innovations such as the Johansen co-integration procedure. In the process of building model for Ethiopian Export of Meat and Meat and Ethiopian Export of leather and leather Products, the possible potential Problems in Multiple Regression Analysis (Autocorrelation, Serial Correlation, Stationary, Heteroskedasticity, cointegration, and Multicollinearity) were Diagnostics, tested, the consequences were identified and the possible remedies were set.

the models used for analysis part were emanated from the nature of data and scope. Consequently, to examine the impact of live animal export on leather products export in Ethiopia, we have applied the Ricardian and HeckscherOhlin mixed models.

ii Model specification for Ethiopian Export of leather and leather Products.

The general model for the impact of live animal export on leather products export is specified as a leather products Export function:-

$$
\ln L Y_{t}=\beta_{0}-\beta_{1} \ln \text { laexn }-\beta_{2} \ln \text { laevusd }+\beta_{3} \ln \text { flvausd }+\beta_{5} \ln \text { rhsvausd }+\varepsilon_{t} .
$$

Where

$\ln L Y_{t}=$ the natural logarithm of Leather Products Volume (in Metric ton)in Millions

ln laex $n=$ the natural logarithm of Live Animal export in number

$\ln$ laevusd $=$ the natural logarithm of Live Animal export value in USD in Millions

$\ln f l v o=$ The natural logarithm of Finished Leather Volume (in Metric ton) in Millions

$\ln r h s v o=$ The natural logarithm of Raw Hides \& Skins Volume (in Metric ton) in Millions

$\beta_{0}=$ The constant term of the model

$\beta_{1}, \beta_{2}, \beta_{3}$ and $\beta_{4}=$ The coefficient of the parameter exported live animals, finished leathers, raw hides and skins a time $\mathrm{t}$

$\epsilon_{i t}=$ The normally distributed error term across time $\mathrm{t}$

The signs under the coefficients denote prior signs of the estimated coefficients. Based on economic theory

\section{Results and discussions}

\subsection{Empirical Analysis}

3.1.1 Leather products and live animals export trend value in millions of USD

The official statistics from Ethiopian Revenue and Customs Authority shows that the total leather product export earning is still about $73 \%$, which had the potential to be converted to other value added products such as shoes, bags, gloves or garment. On the contrary Ethiopia is still importing a huge amount of shoes and leather plastic products from across the world spending millions of hard currency annually. In addition as almost most of shoe making and leather products' accessories such as synthetic sewing thread, plastic linen, shoelaces, zippers, buckles and the like are being imported, the country is a long way from substituting imported shoes and other leather products fully.The relationship between live animal and leather products exports; and their trend through time is presented in figure 1. There should not be such correlation and it is unexpected. But it may support the fact that Ethiopian livestock resource is underutilized. 
Figure 2 : leather products export volume in tones and finished leather export value in USD

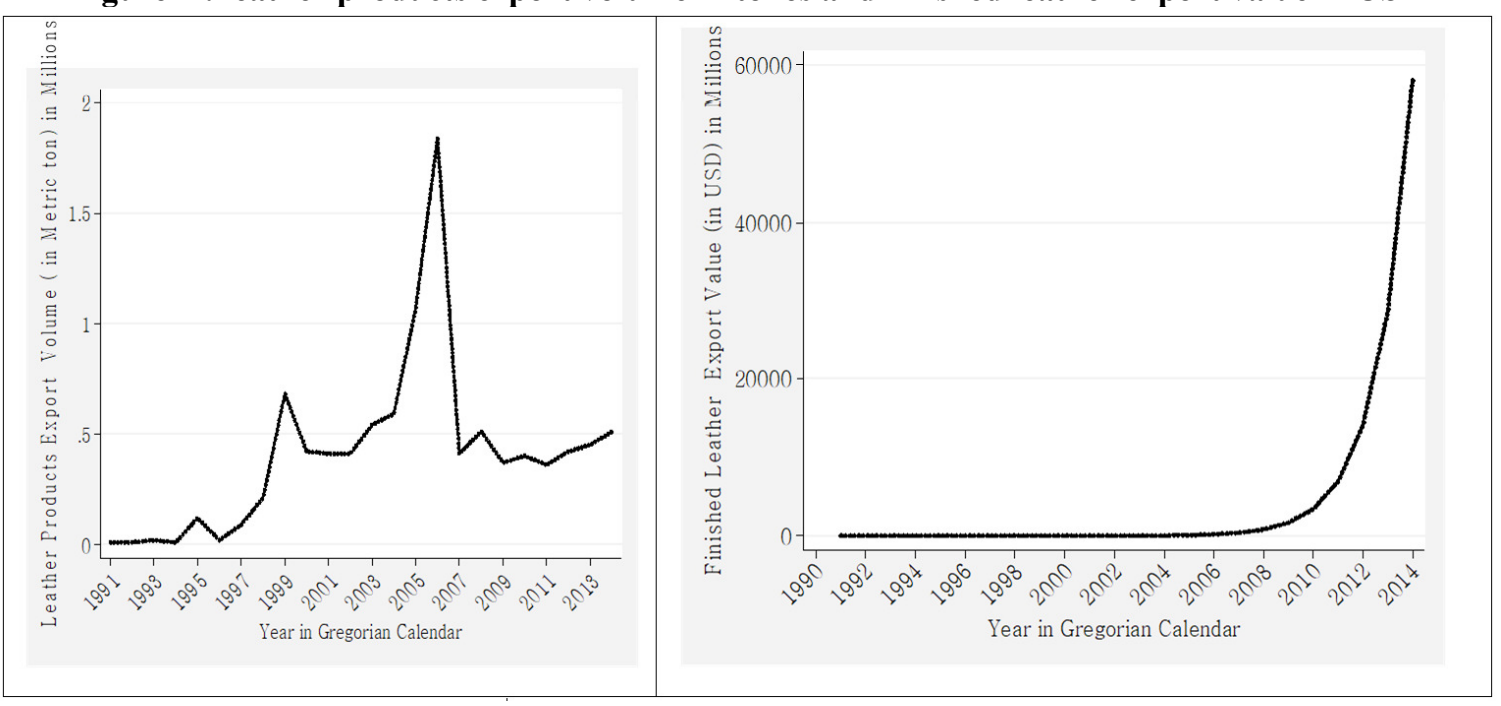

Source: computed by authors (2015)

As the graph shows, since 1991 - 2013 there was an increase in both the finished leather and leather products and reaches its highest level in 2013-2014 especially volume of leather products steeply increased in 2014. Regarding hard currency gained since 1990-2008 the amount of USD was gone relatively constant but, from 20102014 it was highly increased even though the amount of leather products exports remains constant due to the increment of price.

Figure 2 : Two way graph for the Volume of leather products export in tones and live animal export in number

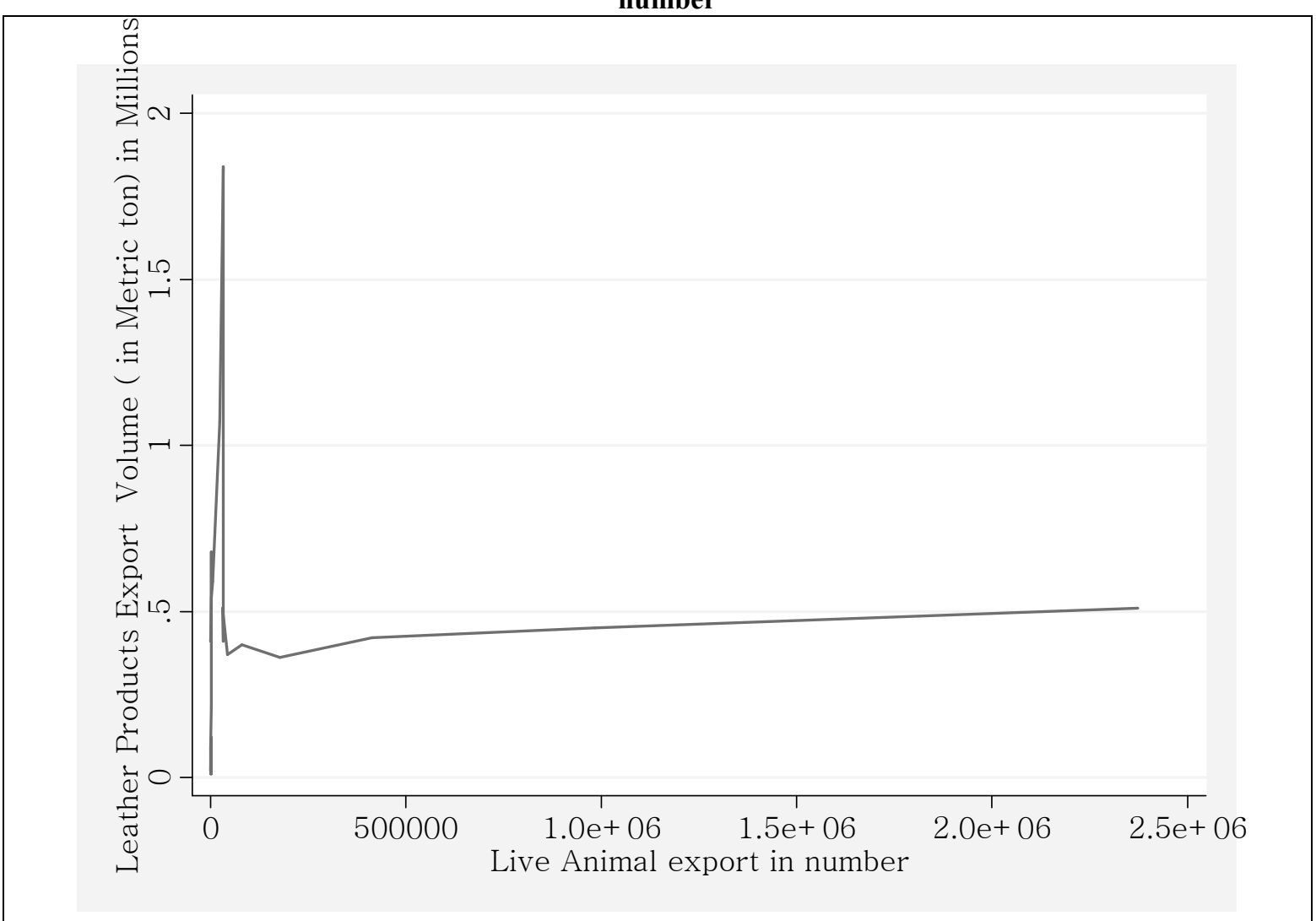

Source: Authors computation, 2015

As figure 2 indicates that leather products export in metric ton increases when the export volume of live animal export increases. However, as the livestock and livestock sector is underutilized the relationship may not be as expected due to high local livestock consumption to be the major sources of hide and skins for the leather products. 
Figure 33: Value of Ethiopian live animal and finished leather export in millions of USD

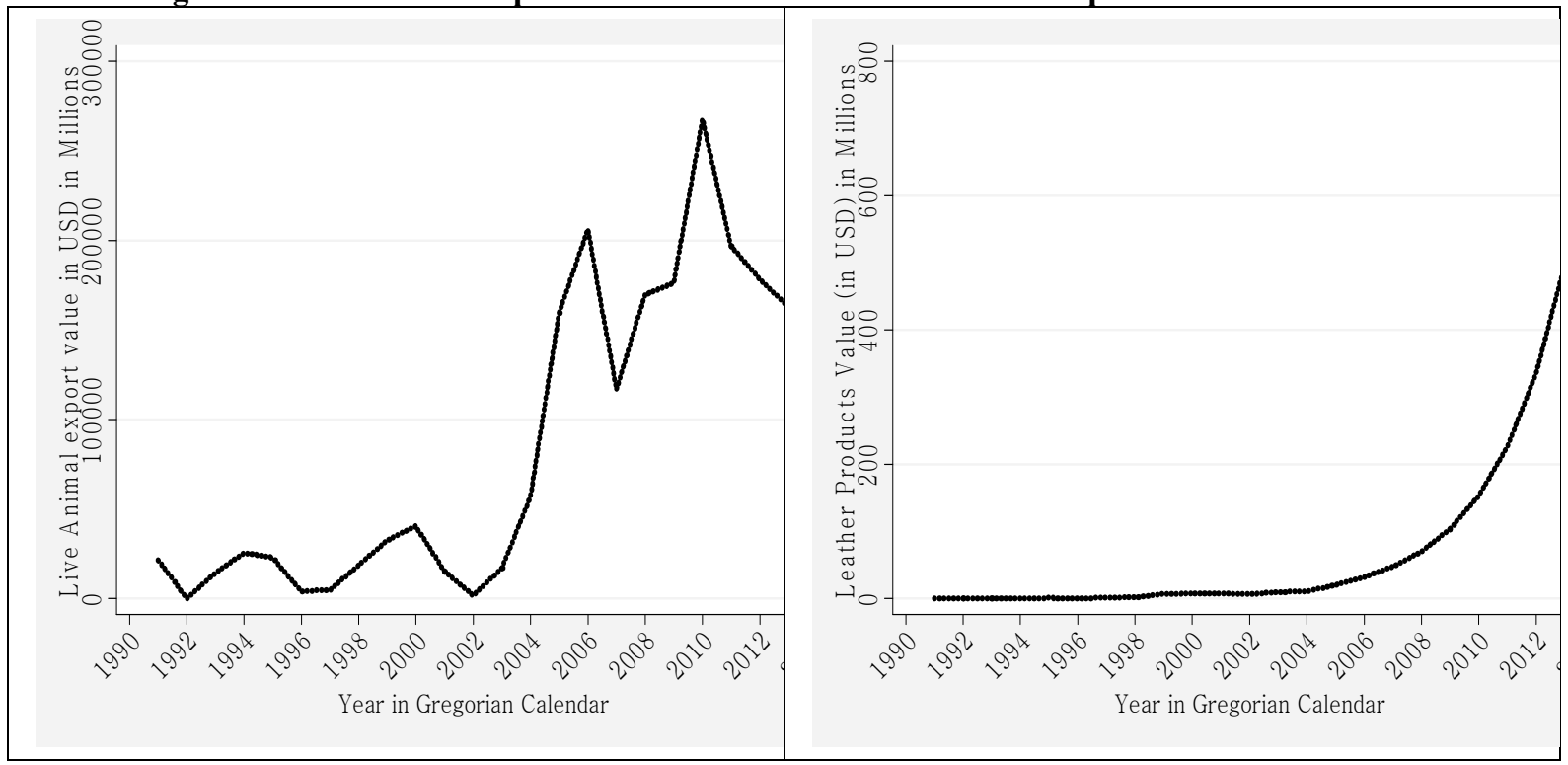

Source: Authors computation, 2015

The amount of USD earned from live animal export throughout the sample period was relatively increased but, it shows ups and downs and reached its highest level at 2010. On the other side value of leather products was static since 1990-2004 But; it was rapidly increased since 2006-2014 and reached its maximum level at 2014.

Figure 4 : Two way graph for Volume of live animal and finished leather export

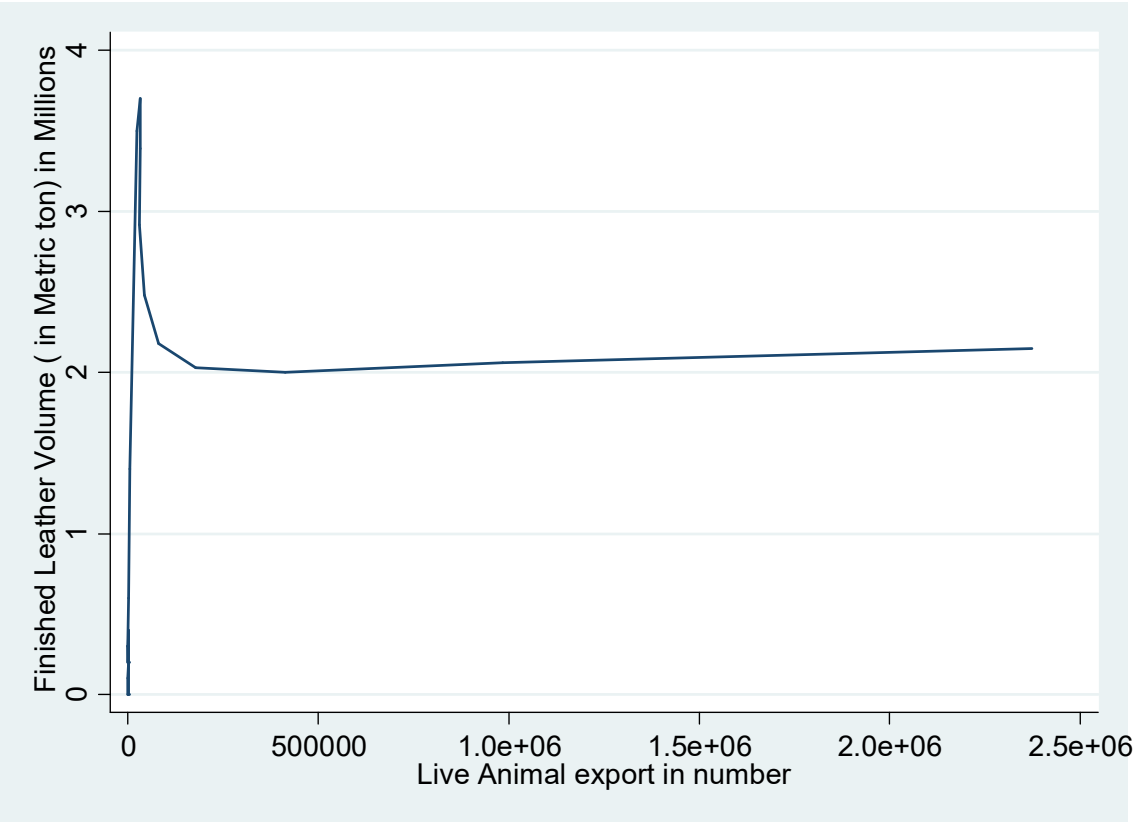

Source: Authors computation, 2015

As the above figure shows there is an increase of export both in live animal and finished leather and starts to boom up. Lack of raw material in the form of finished leather was identified as major problem of shoe industry. While the total demand of leather in the country is 40 million pieces per annum, only producing 21 million pieces (fact sheet, 2014). This implies that, the factories are operating under half their production capacity and Ethiopia is still importing large numbers of shoes, leather and plastic products from across the world, spending millions of hard currency annually.

Moreover, official statistics from the Ethiopian Revenue and Customs Authority show that of the total leather products export, still about 73 per cent is earned from finished leather, which has the potential to be converted into other value added products such as shoes, bags, gloves or garment. In addition as most shoe making and leather products' accessories such as synthetic sewing thread, plastic linen, shoelaces, zippers, buckles and the like are being imported, the country is a long way from fully substituting imported shoes with other leather products. 
Table 1: Summary leather and leather products export statistics of variables

- su year laexn mmvo flvo lpvo rhsvo laevusd mmvausd flvausd lpvausd rhsvausd

\begin{tabular}{r|rrrrr} 
Variable & Obs & Mean & Std. Dev. & Min & Max \\
\hline year & 24 & 2002.5 & 7.071068 & 1991 & 2014 \\
laexn & 24 & 175186.3 & 514173.7 & 0 & 2373895 \\
mmvo & 24 & 364391.4 & 139342.9 & 11519.5 & 572300 \\
flvo & 24 & 1.275417 & 1.280757 & 0 & 3.7 \\
lpvo & 24 & .4116667 & .3977837 & .01 & 1.84 \\
\hline rhsvo & 24 & 143369.8 & 204154.2 & 57600.9 & 1014271 \\
laevusd & 24 & 85689.61 & 84523.25 & 0 & 267773 \\
mmvausd & 24 & 21032.29 & 31065.16 & 226.04 & 108376.6 \\
flvausd & 24 & 4798.317 & 13123.98 & 0 & 58499.12 \\
lpvausd & 24 & 94.5561 & 183.6383 & .05 & 733.6696 \\
\hline rhsvausd & 24 & 17274.06 & 13740.23 & 1991 & 47051
\end{tabular}

Source: Stata output on the basis of secondary data

During the analysis period our country exports on average number of all live animal export 175186.3 and 0.4 million tons of leather and leather products is exported. In addition, minimum, maximum values and their standard deviation are also shown in the table.

Livestock Products: Ethiopia offers a wide range of processed and semi-processed hides and skins to the world market. Some of the products, such as Ethiopian highland sheepskin, which has gained international reputation for making gloves, are well-known for their quality.

The high quality Ethiopian hides and skins exports include: Pickled sheep skin, wet blue sheep skin, crust sheep skin, wet blue goat skin, crust goat skin, crust cow hides, finished garment leather, finished glove leather, lining/upper leather, suede leather, full grain leather, corrected grain leather, embossed leather and patent leather. The export of finished leather and leather products (such as leather garments, foot wear, gloves, bags and other leather articles) is also highly promising.

\section{Export of leather and leather Products model specification}

The general model for the impact of live animal export on leather products export is specified as a leather products Export function:-

$$
\ln L Y_{t}=\beta_{0}-\beta_{1} \ln \text { laexn }-\beta_{2} \ln \text { laevusd }+\beta_{3} \ln \text { flvausd }+\beta_{5} \ln \text { rhsvausd }+\varepsilon_{t}
$$

$\ln L Y_{t}=$ the natural logarithm of Leather Products Volume (in Metric ton) in Millions

ln laexn= the natural logarithm of Live Animal export in number

ln laevusd $=$ the natural logarithm of Live Animal export value in USD in Millions

ln flvausd $=$ The natural logarithm of Finished Leather Value (in USD) in Millions

ln rhsvausd $=$ The natural logarithm of Raw Hides \& Skins Value (in USD) in Millions

$\beta_{0}=$ the constant term of the model

$\beta_{1}, \beta_{2}, \beta_{3}$ and $\beta_{4}=$

the coefficient of the parameter exported live animals, finished leathers, raw hides and skins a time $t$ $\epsilon_{\mathrm{t}}=$ The normally distributed error term accross time $\mathrm{t}$ 
Table 2: Static time series model for the Export of leather Products Volume (in Metric ton) in Millions - reg lnlpvausd lnlaexn lnlaevusd lnflvausd Inrhsvausd

\begin{tabular}{r|crc} 
Source & SS & df & MS \\
\hline $\begin{array}{r}\text { Model } \\
\text { Residual }\end{array}$ & 109.242015 & 4 & 27.3105036 \\
13.755656 & 15 & .917043733 \\
\hline Total & 122.997671 & 19 & 6.47356161
\end{tabular}

$\begin{array}{llr}\text { Number of obs } & =20 \\ \text { F }(4,15) & =29.78 \\ \text { Prob }>\text { F } & =0.0000 \\ \text { R-squared } & 0.8882 \\ \text { Adj R-squared } & =0.8583 \\ \text { Root MSE } & =.95762\end{array}$

\begin{tabular}{|c|c|c|c|c|c|c|}
\hline Inlpvausd & Coef. & Std. Err. & $t$ & $P>|t|$ & [95\% Conf. & Interval] \\
\hline lnlaexn & -1.123318 & .4401402 & -2.55 & 0.022 & -2.061455 & -.1851812 \\
\hline Inlaevusd & .3622954 & .3037172 & 1.19 & 0.251 & -.2850624 & 1.009653 \\
\hline Inflvausd & 1.480641 & .3131984 & 4.73 & 0.000 & .8130744 & 2.148208 \\
\hline Inrhsvausd & .1125082 & .2467238 & 0.46 & 0.655 & -.4133711 & .6383875 \\
\hline _cons & .9064396 & 2.920761 & 0.31 & 0.761 & -5.319016 & 7.131895 \\
\hline
\end{tabular}

Source: Stata output on the basis of secondary data

$\ln L Y_{t}=\beta_{0}-\beta_{1} \ln \operatorname{laexn}-\beta_{2} \ln$ laevusd $+\beta_{3} \ln$ flvausd $+\beta_{\mathbf{5}} \ln$ rhsvausd $+\varepsilon_{\mathrm{t}}$

When we substitute the coefficients by the regression analysis result it becomes as:

$\ln L Y_{t}=0.906-1.123 \ln l a e x n+0.362 \ln$ laevusd $+1.481 \ln$ flvausd $+0.113 \ln$ rhsvausd $+\varepsilon_{t}$ This shows that if live animal export value increase by $1 \%$ there is impact on leather products export $1.123 \%$ decrease i.e. leather products export is inelastic to the value of live animal export.

Table 3: Correlation coefficient among various independent and dependent variables

- corr lnlpvausd lnlaexn lnlaevusd lnflvausd lnrhsvausd

$(\mathrm{obs}=20)$

\begin{tabular}{r|ccccc} 
& lnlpva d & lnlaexn & lnlaev d & lnflva d & Inrhsv d \\
\hline Inlpvausd & 1.0000 & & & & \\
Inlaexn & 0.8461 & 1.0000 & & & \\
Inlaevusd & 0.7132 & 0.8501 & 1.0000 & & \\
Inflvausd & 0.9150 & 0.9739 & 0.7959 & 1.0000 & \\
Inrhsvausd & 0.3254 & 0.4617 & 0.3775 & 0.3989 & 1.0000
\end{tabular}

Source: Stata output on the basis of secondary data

\section{CONCLUSIONS, POLICY IMPLICATIONS AND RECOMMENDATIONS}

This paper has tried to explore impact assessment of live animal export to leather export in Ethiopia. A time series econometric analysis has been applied to determine the significance factors. This has again serious implication in the factories capacity utilization and performance in general which should be implemented to gain foreign currency. We found that there is high export of live animals compared to the export of skin and hide, meat and its products, leather and its products. Raw hides and skins are marketed as judged by visual appraisal without quality grades to pay for better quality.

The leather industry sub sector is identified as one of the strategic investment areas, which can be done with relatively less amount of initial capital using agricultural product (livestock) as its input. Such investments needs a joint venture of the live animals exports and livestock products exports complemented with adding value to its agricultural products, create more jobs, substitute import and generate hard currency for the country. Thus, it implies that building efficient and effective livestock marketing system that is responsive to domestic and international market signals. Technical and policy support is needed to help transform the dominant traditional livestock marketing systems into collaborative marketing system that engage producers and all other market actors involved in the supply chains.

Further research gaps, for effective planning, the country's livestock resources should be studied in detail. So that the type, breeds and their geographical distribution could be known. Moreover, the effect of the international livestock and livestock products marketing system on the Ethiopian market needs to be studied by other researchers to improve the effectiveness and efficiency of the sector. 


\section{References}

CSA, 2015, Agriculture sample survey 2014/2015 (2007 E.C.) (Septmber - January 2014/2015), Volume VII. Report on crop and livetsock product utilization (Private peasant holdings, Meher Season). Central Statistical Agency (CSA): Addis Ababa, Ethiopia.

Engle, R.F. and C.W. J. Granger 1987, 'Cointegration and error correction: representation,

Engle, R.F. and Yoo, B.S. 1987, 'Forecasting and Testing in Cointegrated Systems', Equations: A Co-integration Approach.' Journal of Economic and Social Research vol.4, No.2, pp.71-92.fact sheet, 2014).

Fact sheet: livestock Ethiopia, 2010, 'Livestock in Ethiopia and opportunity analysis for Dutch

Gujarati, D.N., 2004, Basic Econometrics, 4th Edition, McGraw-Hill, New York.

MoA and ILRI (Ministry of Agriculture and International Livestock Research Institute), 2013. Dairy value chain vision and strategy for Ethiopia. Addis Ababa, Ethiopia: Ministry of Agriculture and International Livestock Research Institute.

\section{Appendix}

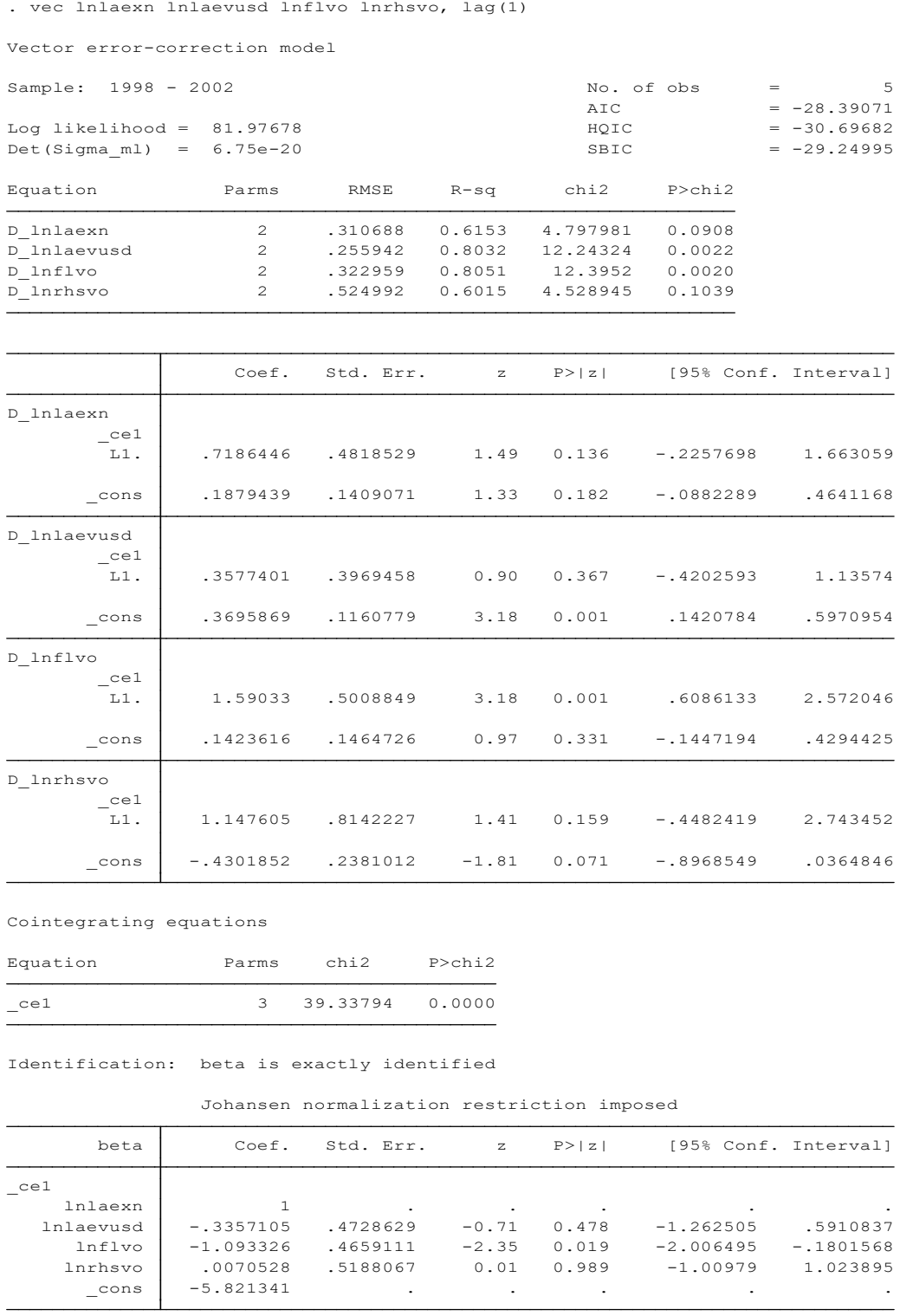

\section{Websites visited}

http://www.afdb.org

https://www.cia.gov/library/publications/the-world-factbook/fields/2050.html http://www.economywatch.com/ http://faostat.fao.org/site/342/default.aspx

http://www.indexmundi.com/

http://www.nbe.gov.et/publications/annualreport.htm 
http://www.state.gov/p/nea/ci/ae http://www.state.gov/p/nea/ci/sa http://www.worldbank.org/

4.1.1. Stationarity and unit root test result

1. $|\rho|>1$ Series is non-stationary and explosive. Past shocks have a greater impact than current ones. These situations are uncommon and I am not looked at how to deal with them.

2. $|\rho|<1$ Series is stationary and the effects of shocks die out exponentially according to $\rho$. The series reverts to its mean. We have already seen what to do with these.

3. $|\rho|=1$ Series is non-stationary, shocks persist at full force, and the series is not mean-reverting. This is the random walk model and as we saw, the variance increases with $t$ and so we have the infinite variance problem. Typically, we are interested in determining between the last two scenarios i.e. $|\rho|<1$ or $\mathrm{j}|\rho|=1$. The question is whether we have a unit root or not (also known as a random walk) i.e. $j|\rho|=1$ ? The first thing in time series analysis is get a view of the time series plot of the variables in the analysis. This helps to identify if there exists a non stationarity problem in our data, as most of time series variables possess the problem. The main findings of the study are summarized as follows:

To estimate the long-run relationship of the variables of the model, the researcher plotted the behaviours of the variables over time. However, since graphical inspection is not sufficient to address the issue at hand, the unit root characteristics of the data are examined using the Augmented Dickey-Fuller (ADF) test. The result of the Augmented Dickey-Fuller (ADF) test as illustrated in the table 12, at levels since the computed ADF value in absolute terms is less than the $1 \%, 5 \%$ or $10 \%$ critical values disregarding the sign, it implies that the time series variables are non-stationary. But, as can be seen from the same table it is the first differences of the series that make them stationary. All the variables are stationary in their first differences, implying they are integrated of order one [I (1)]. Therefore, the first-differenced series can be used in the time series analysis. If one non stationary time series is regressed on another non stationary time series, the results are likely to be spurious. However, if the two series are co integrated, the regression results would not be spurious. As mentioned in Gujrati (2004), combining two or more time series that are integrated of different order may result in biased estimates.

Table 1 : Result of augmented Dickey-Fuller test for stationarity and unit root, without constant lags (1).

\begin{tabular}{|l|l|l|l|l|l|}
\hline \multicolumn{1}{|c|}{ Variables } & \multicolumn{1}{c|}{$1 \%$} & \multicolumn{1}{c|}{$5 \%$} & \multicolumn{1}{c|}{$10 \%$} & \multicolumn{1}{c|}{ Decisions } \\
\hline Lnlaexn & 2.312 & -2.660 & -1.950 & -1.600 & Reject $H_{0}$ at $10 \%$ \\
\hline Inmmvo & -0.210 & -2.660 & -1.950 & -1.600 & Reject $H_{0}$ at $10 \%$ \\
\hline Lnflvo & -2.209 & -2.660 & -1.950 & -1.600 & Reject $H_{0}$ at $5 \%$ \\
\hline Lnlpvo & -2.196 & -2.660 & -1.950 & -1.600 & Reject $H_{0}$ at $1 \%$ \\
\hline Lnrhsvo & 0.070 & -2.660 & -1.950 & -1.600 & Reject $H_{0}$ at $10 \%$ \\
\hline lnlaevusd & 0.301 & -2.660 & -1.950 & -1.600 & Reject $H_{0}$ at $10 \%$ \\
\hline lnmmvausd & 1.419 & -2.660 & -1.950 & -1.600 & Reject $H_{0}$ at $10 \%$ \\
\hline Inflvausd & 5.652 & -2.660 & -1.950 & -1.600 & Reject $H_{0}$ at $1 \%$ \\
\hline lnlpvausd & 0.538 & -2.660 & -1.950 & -1.600 & Reject $H_{0}$ at $10 \%$ \\
\hline lnrhsvausd & -0.288 & -2.660 & -1.950 & -1.600 & Reject $H_{0}$ at $10 \%$ \\
\hline
\end{tabular}

$H_{0}=$ the series has a unit root (non-stationary)

We may believe that there is non-stationarity for other reasons than a unit root. One reason is that there may be drift. It is possible to test for both a unit root and drift with the following model.

Table 2 : Result of augmented Dickey-Fuller test for stationarity and unit root, constant (drift, No trend) lags (1).

\begin{tabular}{|l|l|l|l|l|l|}
\hline \multicolumn{1}{|c|}{ Variables } & \multicolumn{1}{c|}{ Coef. } & \multicolumn{1}{c|}{ t- Statistic } & \multicolumn{1}{c|}{$\mathrm{P}>|\mathrm{t}|$} & \multicolumn{2}{c|}{$[95 \%$ Conf. Interval] } \\
\hline Lnlaexn & .0633481 & 0.90 & 0.377 & -.083372 & .2100682 \\
\hline Lnmmvo & -.5109109 & -2.69 & 0.014 & -.9061729 & -.1156489 \\
\hline Lnflvo & -.1509733 & -2.03 & 0.058 & -.3076176 & .005671 \\
\hline Lnlpvo & -.236479 & -2.12 & 0.046 & -.4680938 & -.0048643 \\
\hline Lnrhsvo & .4155518 & 7.42 & 0.000 & .2990543 & .5320494 \\
\hline Lnlaevusd & -.2235185 & -1.54 & 0.139 & -.5268016 & .0797646 \\
\hline lnmmvausd & -.0506755 & -0.61 & 0.548 & -.2233875 & .1220366 \\
\hline Lnflvausd & .0525842 & 1.78 & 0.093 & -.0097164 & .1148847 \\
\hline Lnlpvausd & -.0497952 & -0.77 & 0.449 & -.1841309 & .0845405 \\
\hline lnrhsvausd & -.5368623 & -2.78 & 0.011 & -.9381535 & -.1355711 \\
\hline$H_{0}=$ The series has a unit root and drift (non-stationary) with no linear time trend \\
\hline
\end{tabular}

Instead of there being a drift, we may have a series with a deterministic trend 
Table 3 : Result of augmented Dickey-Fuller test for stationerity unit root (constant and Time trend) lags (1).

\begin{tabular}{|l|l|l|l|l|l|}
\hline \multicolumn{1}{|c|}{ Variables } & \multicolumn{1}{c|}{ Coef. } & \multicolumn{1}{c|}{$\mathrm{t}$ - Statistic } & \multicolumn{1}{c|}{$\mathrm{P}>|\mathrm{t}|$} & \multicolumn{2}{c|}{ [95\% Conf. Interval] } \\
\hline Lnlaexn & -.2392365 & -1.75 & 0.098 & -.527131 & .048658 \\
\hline Lnmmvo & -.5657741 & -2.76 & 0.012 & -.9932329 & -.1383154 \\
\hline Lnflvo & -.2043316 & -1.55 & 0.141 & -.4837892 & .075126 \\
\hline Lnlpvo & -.3722432 & -2.16 & 0.043 & -.7320647 & -.0124218 \\
\hline Lnrhsvo & .3867574 & 4.22 & 0.000 & .1953976 & .5781172 \\
\hline lnlaevusd & -.524706 & -2.53 & 0.021 & -.9596069 & -.089805 \\
\hline lnmmvausd & -.545708 & -2.79 & 0.011 & -.9535078 & -.1379081 \\
\hline lnflvausd & -.1011915 & -1.37 & 0.191 & -.2583241 & .0559411 \\
\hline lnlpvausd & -.9545864 & -4.26 & 0.000 & -1.421585 & -.4875875 \\
\hline lnrhsvausd & -.5582694 & -2.85 & 0.010 & -.9675045 & -.1490343 \\
\hline$H_{0}=$ The series has a unit root and drift (non-stationary) with no linear time trend \\
\hline
\end{tabular}

3.1.1. Co-integration analysis and Error Correction Model

Export volume is regressed on the value of meat and meat product export, export volume of live animals and dummy of import ban and the residuals from this regression were subjected to unit root test. The Phillips Perron test statistic is higher than the absolute value of MacKinnon critical value at $5 \%$ level; meaning the residual is stationary. Co-integrating regression Durbin Watson test (CRDW); which could be used as a quick approximate result, is also applied to check whether long run relationship exists between the variables. The results suggested that there is a co-integrating relationship in the long run export volume of meat and meat products export equation. The value of F - statistic shows all the independent variables are non-zero. Furthermore, Durbin Watson (D.W.) statistic reveals the existence of autocorrelation.

Having established a long run relationship among the variables in equation as a means of reconciling the short-run behaviour of an economic variable with its long-run behaviour it is appropriate to formulate Error Correction Model (ECM).According to Engle and Granger (1987) the mathematical formulation of error correction model for Ethiopian exports is as follows: Considering Enders, 1995 argument, the last step in the estimation of error-correction models is checking of models adequacy. After running the conventional OLS regression, its assumptions need to be tested. Assumptions like residual normality, homoskedasticity, and no multi-co linearity must be fulfilled for the model to be valid. In addition, link test is made to test for specification error; whether we need new variables in our model. In practice when hetroscedasticity is believed to exist, to deal with the problem hetroscedasticity -robust standard errors is recommended. This is applied to the long run model. Generally, the implications of these results is that both the short run and long run export demand models of Ethiopia are correctly specified and can be predicted using the specified independent variables.

Table 4 : Vector error-correction model for Export Leather products

\begin{tabular}{|l|l|l|l|l|}
\hline & \multicolumn{1}{|c|}{$\Delta$ lnmmvo } & \multicolumn{1}{|c|}{$\Delta$ lnlaexn } & \multicolumn{1}{|c|}{ Slnlaevusd } & \multicolumn{1}{c|}{$\Delta$ lnmmvausd } \\
\hline Constant & -0.0068857 & 0.4179328 & 0.1009454 & 0.201789 \\
\hline & $(0.252197)^{*}$ & $(0.1808724)$ & $(0.2288824)^{*}$ & $(0.1305853)^{*}$ \\
\hline ce1 L1. & .0173422 & -.051829 & .0105444 & .102662 \\
\hline & $(0.0649086)$ & $(0.0465516)$ & $(0.0589081)$ & $(0.0336091)$ \\
\hline
\end{tabular}

*indicates that rejection of the null hypothesis at $5 \%$ level of significance

After fitting a VAR, we may want to know whether one variable "Granger-causes" another (Granger 1969). A variable $\mathrm{x}$ is said to Granger-cause a variable $\mathrm{y}$ if, given the past values of $\mathrm{y}$, past values of $\mathrm{x}$ are useful for predicting y. Common methods for testing Granger causality is to regress y on its own lagged values and on lagged values of $\mathrm{x}$ and test the null hypothesis that the estimated coefficients on the lagged values of $\mathrm{x}$ are jointly zero. Failure to reject the null hypothesis is equivalent to failing to reject the hypothesis that $\mathrm{x}$ does not Granger-cause y.

For each equation and each endogenous variable that is not the dependent variable in that equation, vargranger computes and reports Wald tests that the coefficients on all the lags of an endogenous variable are jointly zero. For each equation in a VAR, vargranger tests the hypotheses that each of the other endogenous variables does not Granger-cause the dependent variable in that equation. 
Table 5 : Granger causality Wald tests for Meat Products Export model

\begin{tabular}{|c|c|c|c|c|}
\hline Equation & Excluded & chi2 & $d f$ & Prob $>$ chi2 \\
\hline lnmmvo & lnlaexn & .23394 & 1 & 0.629 \\
\hline lnmmvo & lnlaevusd & .50802 & 1 & 0.476 \\
\hline lnmmvo & Inmmvausd & .22299 & 1 & 0.637 \\
\hline lnmmvo & ALL & 1.4526 & 3 & 0.693 \\
\hline lnlaexn & lnmmvo & .17643 & 1 & 0.674 \\
\hline Inlaexn & Inlaevusd & 4.3892 & 1 & 0.036 \\
\hline lnlaexn & Inmmvausd & 7.5137 & 1 & 0.006 \\
\hline lnlaexn & ALL & 12.435 & 3 & 0.006 \\
\hline Inlaevusd & lnmmvo & 1.7236 & 1 & 0.189 \\
\hline Inlaevusd & lnlaexn & .3364 & 1 & 0.562 \\
\hline Inlaevusd & Inmmvausd & 6.0821 & 1 & 0.014 \\
\hline Inlaevusd & ALL & 11.913 & 3 & 0.008 \\
\hline Inmmvausd & Inmmvo & 1.6365 & 1 & 0.201 \\
\hline Inmmvausd & lnlaexn & 10.079 & 1 & 0.001 \\
\hline Inmmvausd & Inlaevusd & 9.6185 & 1 & 0.002 \\
\hline lnmmvausd & ALL & 11.216 & 3 & 0.011 \\
\hline
\end{tabular}

The null hypothesis is 'Inlaexn, lnlaevusd, and lnmmvausd does not Granger-cause lnmmvo'. In the majority cases, we can reject the null that each variable does not Granger-cause the other

Table 6 : Granger causality Wald tests for Leather Products Export model

\begin{tabular}{|c|c|c|c|c|}
\hline Equation & Excluded & chi2 & $d f$ & Prob > chi2 \\
\hline Inlaexn & lnlaevusd & .9277 & 1 & 0.335 \\
\hline Inlaexn & lnflvo & 1.1247 & 1 & 0.289 \\
\hline Inlaexn & Inrhsvo & .1964 & 1 & 0.658 \\
\hline lnlaexn & ALL & 4.0804 & 3 & 0.253 \\
\hline Inlaevusd & lnlaexn & .89458 & 1 & 0.344 \\
\hline Inlaevusd & lnflvo & 3.409 & 1 & 0.065 \\
\hline Inlaevusd & lnrhsvo & .66507 & 1 & 0.415 \\
\hline Inlaevusd & ALL & 8.736 & 3 & 0.033 \\
\hline lnflvo & lnlaexn & .76123 & 1 & 0.383 \\
\hline lnflvo & lnlaevusd & .20978 & 1 & 0.647 \\
\hline lnflvo & lnrhsvo & .89443 & 1 & 0.344 \\
\hline lnflvo & ALL & 5.2667 & 3 & 0.153 \\
\hline Inrhsvo & lnlaexn & 5.8052 & 1 & 0.016 \\
\hline Inrhsvo & lnlaevusd & .12352 & 1 & 0.725 \\
\hline Inrhsvo & lnflvo & 24.003 & 1 & 0.000 \\
\hline Inrhsvo & ALL & 24.667 & 3 & 0.000 \\
\hline
\end{tabular}

The null hypothesis is 'Inlaevusd, Inflvo, and lnrhsvo not Granger-cause lnlaexn'. In the majority cases, we can reject the null that each variable does not Granger-cause the other the basis of secondary data (2014) 